\title{
Combination of psychotherapy and benzodiazepines versus either therapy alone for panic disorder: a systematic review Norio Watanabe*1, Rachel Churchill ${ }^{2}$ and Toshi A Furukawa ${ }^{1}$
}

Address: ${ }^{1}$ Department of Psychiatry and Cognitive-Behavioral Medicine, Nagoya City University Graduate School of Medical Sciences, Nagoya, Japan and 2Section of Evidence-Based Mental Health, Health Service and Population Research Department, Institute of Psychiatry, King's College London, University of London, UK

Email: Norio Watanabe* - noriow@med.nagoya-cu.ac.jp; Rachel Churchill - R.Churchill@iop.kcl.ac.uk;

Toshi A Furukawa - furukawa@med.nagoya-cu.ac.jp

* Corresponding author

Published: 14 May 2007

BMC Psychiatry 2007, 7:18 doi:10.1186/1471-244X-7-18

This article is available from: http://www.biomedcentral.com/I47I-244X/7/I8

(C) 2007 Watanabe et al; licensee BioMed Central Ltd.

This is an Open Access article distributed under the terms of the Creative Commons Attribution License (http://creativecommons.org/licenses/by/2.0), which permits unrestricted use, distribution, and reproduction in any medium, provided the original work is properly cited.
Received: 27 September 2006

Accepted: 14 May 2007

\begin{abstract}
Background: The efficacy of combined psychotherapy and benzodiazepine treatment for panic disorder is still unclear despite its widespread use. The present systematic review aims to examine its efficacy compared with either monotherapy alone.

Methods: All randomised trials comparing combined psychotherapy and benzodiazepine for panic disorder with either therapy alone were identified by comprehensive electronic search on the Cochrane Registers, by checking references of relevant studies and of other reviews, and by contacting experts in the field. Two reviewers independently checked eligibility of trials, assessed quality of trials and extracted data from eligible trials using a standardized data extraction form. Our primary outcome was "response" defined by global judgement. Authors of the original trials were contacted for further unpublished data. Meta-analyses were undertaken synthesizing data from all relevant trials.
\end{abstract}

Results: Only two studies, which compared the combination with behaviour (exposure) therapy, met our eligibility criteria. Both studies had a 16-week intervention. Unpublished data were retrieved for one study. The relative risk for response for the combination was $1.25(95 \% \mathrm{Cl}: 0.78$ to 2.03$)$ during acute phase treatment, 0.78 (0.45 to I.35) at the end of treatment, and 0.62 (0.36 to I.07) at 6-12 months follow-up. Some secondary outcomes hinted at superiority of the combination during acute phase treatment.

One study was identified comparing the combination to benzodiazepine. The relative risk for response was I.57 (0.83 to 2.98$), 3.39$ (I.03 to II.2I, statistically significant) and $2.3 \mathrm{I}$ ( 0.79 to 6.74 ) respectively. The superiority of the combination was observed on secondary outcomes at all the time points. No subgroup analyses were conducted due to the limited number of included trials.

Conclusion: Unlike some narrative reviews in the literature, our systematic search established the paucity of high quality evidence for or against the combined psychotherapy plus benzodiazepine therapy for panic disorder. Based on limited available published and unpublished data, however, the combined therapy is probably to be recommended over benzodiazepine alone for panic disorder with agoraphobia. The combination might be superior to behaviour therapy alone during the acute phase, but afterwards this trend may be reversed. We know little from these trials about their adverse effects. 


\section{Background}

Panic disorder is characterized by the repeated occurrence of unexpected panic attacks, i.e. abrupt strong fears with anticipation of death, often accompanied by somatic symptoms such as palpitations, dyspnoea or faintness. Applying recent diagnostic criteria including DSM-III-R and DSM-IV, epidemiological studies have reported annual prevalence at 2.3\% [1], 2.2\% [2] and 2.7\% [3]. One-third to one-half of patients with panic disorder in community samples is also diagnosed to have agoraphobia [4].

Two broad categories of treatment have been shown to be effective in treating panic disorder; one is pharmacotherapy including benzodiazepines and antidepressants, and the other is psychotherapy including behaviour therapy and cognitive behaviour therapy.

Recent guidelines recommended selective serotonin reuptake inhibitors (SSRIs) as the first-line pharmacological treatment and argued that its efficacy was comparable to psychotherapy alone [5]. However, the most recently published systematic review has shown that the combined antidepressant plus psychotherapy was superior to either monotherapy in the short term, and also superior to antidepressant alone but was as good as psychotherapy alone in the long term [6].

Benzodiazepines have been the most frequently prescribed medication for patients with panic disorder $[7,8]$. There are some advantages to treatment with benzodiazepines in that they lead to effects on panic attacks earlier [9] with milder adverse effects than antidepressants [10]. Nevertheless, the use of benzodiazepines has been associated with sedation, reduced coordination, cognitive impairments [11], increased accident proneness [12,13] and development of dependence [14], and it has been reported that a rebound of panic attacks can occur during taper [15].

Psychotherapy has also been reported to be effective in treating panic disorder [16-23] and is a potential alternative to the use of benzodiazepines without any adverse drug effects. On the other hand, psychotherapy has been said to need longer time to show its effects on panic disorder than benzodiazepines [9].

A benzodiazepine and psychotherapy are widely used together in practice. In a specialized clinic for cognitivebehaviour therapy, over three quarters of the patients were given benzodiazepines [24]. However, little evidence exists so far for any additional benefit to combination therapy and, if so, whether the benefit is worth the extra cost of combining two treatments [25-27]. Furthermore, some observational studies suggested that benzodi- azepines actually interfered with cognitive-behavioral interventions [28-31], while others [32,33] suggested otherwise. We therefore need stronger evidence to get a more precise estimate of their efficacy and safety.

The primary objective of the present systematic review is to comprehensively search for and synthesize the best evidence on the combined psychotherapy plus benzodiazepines in comparison with either treatment alone for panic disorder with or without agoraphobia, in both the short- and long-term.

\section{Methods}

\section{Inclusion criteria}

All relevant randomised controlled trials comparing combined benzodiazepine and psychotherapy with either therapy alone in adult patients with panic disorder with or without agoraphobia, diagnosed according to operationalized criteria such as DSM-III, DSM-III-R, DSM-IV or ICD-10 were included. Patients with secondary mental disorders were included but the effect of this decision was to be examined in a sensitivity analysis.

For psychotherapies, individual or group forms of psychological treatments, such as cognitive therapy, behaviour therapy, cognitive-behaviour therapy and psychodynamic therapy were included regardless of their frequency and duration.

Our primary outcome both of short-term and long-term efficacy was "response" defined by global judgement, such as "very much" or "much" improved in Clinical Global Impressions - Improvement scale if the data were available. When global assessment data were not available, reduction from the baseline in phobic avoidance was used for response. We did not take account of the number or severity of panic attacks as our definition of response, because it was not panic but rather phobic avoidance that has been shown to correlate with the severity of panic disorder with agoraphobia [34].

We also examined global severity, frequency or severity of panic attacks, phobic avoidance, general anxiety, depression, social functioning, patients' satisfaction and cost effectiveness.

Adverse effects were evaluated by looking at the number of dropouts due to adverse effects, and total number of dropouts for any reason was examined as a proxy measure of treatment acceptability.

\section{Identification of trials}

We electronically searched the Cochrane Collaboration Depression, Anxiety and Neurosis Group Registers (CCDAN REGISTERS) on October 11, 2005. This compre- 
hensive register is updated regularly adding the results of searches of The Cochrane Library, MEDLINE (1966-), EMBASE (1980-), CINAHL (1982-), PsycINFO (1974-), PSYNDEX (1977-) and LILACS (1982-1999) and handsearches of major psychiatric, medical journals, conference proceedings and trial registers. Moreover, the register is being coded continuously with respect to characteristics of studies such as the kind of interventions and their concomitant use, by looking through the full article of relevant studies manually. The studies already coded are being stored in CCDANCTR-Studies and the others in CCDANCTR-References. The register contains more than 24,000 records on trials comparing treatment options within the scope of the CCDAN. One complementary search for additional relevant trials was conducted with The Cochrane Central Register of Controlled Trials (CENTRAL).

Three independent reviewers (NW, RC and TAF) examined titles and abstracts of studies identified by the electronic searches and then checked full articles for eligibility. To identify further trials, references of these selected studies and of other review papers were also checked, representative studies were subjected to SciSearch and experts in the field were contacted. No language restriction was imposed.

\section{Quality assessment and data extraction}

Two independent reviewers (NW and TAF) assessed the methodological quality of the selected studies.

The criteria for quality assessment were based on recommendations in the Cochrane Handbook for Systematic Reviews of Interventions [35], which focused on the quality of allocation concealment. We also rated whether at least one outcome measure was assessed by an independent assessor blind to treatment allocation. In addition, regarding psychotherapy, its adequacy is considered to be essential for effective treatment, and to depend on the expertise of the practitioner and the therapist's adherence to a particular form of therapy. We assessed the adequacy of psychotherapy in each study and if the authors gave sufficiently detailed description of the therapy procedure, and if audiotapes of the psychotherapy process were examined by a third reviewer. The three reviewers independently extracted data from the original reports using data extraction forms. For studies where exact numbers of responders were not presented but only their means and standard deviations (SDs) of the global severity measure, we imputed response rates by using a validated imputation method [36] in order to conduct intention-to-treat (ITT) analyses as described below. Any disagreement was resolved by consensus between all three reviewers.

\section{Data synthesis}

Data were double-entered into Review Manager 4.2 to check for accuracy. Meta-analyses were then performed.

For dichotomous outcomes, ITT analysis was adopted. When dropouts were excluded from any assessment in the primary studies (for example, those who never returned for assessment after randomisation), they were considered non-responders both in the combination group and monotherapy group. Relative risks (RR) and their 95\% confidence intervals were calculated using random effects model rather than a fixed effects model because of its generalizability [37].

For continuous outcomes, the standardized weighted mean difference (SMD) was calculated for end-point data of completers only using random effects model.

Heterogeneity, which refers to variability among studies in a systematic review and generally derives from clinical, methodological or statistical diversity [35], was assessed by Chi-square statistics and I-square statistics [38]. When substantive heterogeneity was found ( $\mathrm{p}<0.10$ or Isquared $>30 \%$ ), sources were investigated.

We also planned sub-group analyses in terms of types of psychotherapy, and sensitivity analyses to examine robustness of the review's findings, by a) limiting to trials with patients who had no comorbid physical or mental disorders, b) excluding trials with no regular concomitant use of an antidepressant, c) limiting to trials where the psychotherapy used had high adequacy, and d) limiting to trials where both allocation concealment and assessor blindness were noted.

\section{Results \\ Description of studies}

The electronic search identified 12 studies from CCDANCTR-Studies, 123 from CCDANCTR-References and 67 from CENTRAL. Browsing their titles and abstracts, 60 articles were identified by either of the two independent reviewers as possible candidates and their full copies were obtained. Ten studies were then selected to proceed to strict eligibility check stage. During further reference search, SciSearch and personal contacts, one additional study possibly eligible was identified. Two independent reviewers examined the strict eligibility of these 11 studies and 4 studies remained. The inter-rater reliability of the items of strict eligibility criteria was percentage agreement of $96 \%$ and kappa of 0.71 (95\%CI: 0.37 to 1.0$)$. Discrepancies were resolved by consensus. Two of the studies were finally excluded because benzodiazepine was given only on the day of the visit [39] or because only the number of completers in both interven- 
tion and control groups were described [40] (Table 1), and we arrived at two studies $[20,41]$ (Table 2).

Marks and his colleagues provided two comparisons, which comprised of one comparison between combination therapy and psychotherapy alone and the other between combination and benzodiazepine alone [20,34,42-52]. Wardle and her colleagues provided a comparison between combination therapy and psychotherapy alone $[41,53]$. We therefore obtained data for a total of 243 participants from two studies (Table 3).

Regarding diagnostic criteria, the former study included patients who had panic disorder with agoraphobia, and the latter included patients with agoraphobia. Though the latter did not mention panic disorder in diagnostic inclusion criteria, contact with the authors revealed that all patients in the study had some panic attacks and almost all of the patients would be qualified as panic disorder with agoraphobia according to DSM-IV.

The former employed alprazolam as a benzodiazepine and exposure as psychotherapy; the latter did diazepam as a benzodiazepine and exposure as psychotherapy. The duration of interventions was 16 weeks in both studies, which included drug withdrawal (Table 2).

With regard to outcomes, means and standard errors (SEs) of clinical global rating were reported at all the time points of assessment in one study [49]. SDs were calculated from SEs and the numbers of responders ("very much or "much" improved on Clinician's Global Improvement) were imputed. The other study assessed clinical global rating only at the 12-months follow-up assessment [41], so we defined responders as patients with $50 \%$ reduction from baseline on the mobility when alone subscale (MAL) of the Mobility Inventory [54]. No study reported on patients' satisfaction and economic costs. The numbers of patients who dropped out due to side effects or suffered from withdrawal symptoms upon cessation of treatment were not specified either. No information is given about relapse rates during follow-up in both of the studies. Additional treatment (taking benzodiazepines after the treatment period) is reported in one study [41], but the number of participants in each of the intervention and the control arms is not given.

With regard to study quality, neither study described concealment of allocation but both reported having kept assessors blind. The inter-rater reliability of these two validity criteria was $100 \%$ agreement for both. Regarding adequacy of the psychotherapies provided, one study was rated high [20], and the other moderate [41].

\section{Psychotherapy plus Benzodiazepine versus Psychotherapy} Acute phase treatment

Two comparisons from two studies were included between combined psychotherapy and benzodiazepine versus psychotherapy alone in the acute phase treatment (Table 3). The data suggested the relative risk (RR) for response for the combination was 1.25 (95\% CI: 0.78 to 2.03; $\mathrm{P}=0.35)$ at 2 months during the acute phase treatment (Figure 1). No heterogeneity was observed $\left(\chi^{2}=\right.$ $\left.0.00, \mathrm{df}=1, \mathrm{P}=0.95 ; \mathrm{I}^{2}=0.0 \%\right)$.

With regard to secondary outcomes, although combination therapy was not shown to have significant superiority to psychotherapy alone in terms of global severity of panic disorder (Figure 2), the combination therapy was superior in panic frequency and social functioning (panic frequency: SMD $0.38 ; 95 \% \mathrm{CI} 0.02$ to $0.72 ; \mathrm{P}=0.04$, social functioning: SMD $0.51 ; 95 \% \mathrm{CI} 0.01$ to $1.01 ; \mathrm{P}=0.05$ ).

Both combination therapy and psychotherapy alone groups had similar dropout rates ( $\mathrm{RR}=0.81,95 \% \mathrm{CI}: 0.47$ to $1.38 ; \mathrm{P}=0.44$ ).

\section{After the end of acute treatment}

Little difference between combination therapy and psychotherapy alone groups was shown on the whole $(\mathrm{RR}=$

Table I: Reasons for excluding studies

\begin{tabular}{ll}
\hline Study & Reason for exclusion \\
\hline Chambless et al. 1982 [59] & The combination arm used barbiturates, not benzodiazepines. \\
Chouinard et al. 1982 [60] & Some participants had combination therapy but their outcomes were not reported. \\
Craske 199I [6I] & The interventions did not involve psychotherapy combined with benzodiazepine. \\
Echeburua et al. 1993 [62] & Participants were diagnosed as agoraphobia but had no panic attack. \\
Hafner and Marks 1976 [39] & Participants did not take benzodiazepine on regular basis but on the day of visit only. \\
Johnston and Gath 1973 [63] & Participants did not take benzodiazepine on regular basis but on the day of flooding only. \\
Lopez-Alonso and Gomze-Jarabo 2000 [40] & Only the number of completers in both intervention and control groups were described. \\
Otto et al. I993 [64] & All participants were prescribed benzodiazepine and this was then tapered. \\
Riley et al. 1995 [65] & The interventions did not involve the combination of psychotherapy and benzodiazepine. \\
Spiegel et al. I994 [66] & All participants were prescribed benzodiazepine and this was then tapered. \\
Whitehead et al. 1978 [67] & All participants had animal phobia, not panic disorder. \\
\hline
\end{tabular}




\begin{tabular}{|c|c|c|c|c|c|c|}
\hline Study & Participants & $\begin{array}{l}\text { Acute phase } \\
\text { interventions }\end{array}$ & $\begin{array}{l}\text { Maintenance } \\
\text { interventions }\end{array}$ & Follow-up & Definition of response & Other outcomes \\
\hline Marks I993 [20] & $\begin{array}{l}\text { Diagnosis: DSM-III PD with } \\
\text { AG } \\
\text { Mean duration: } 8 \text { years } \\
\text { Mean age: } 35 \text { years } \\
81 \% \text { female } \\
\text { Psychiatric comorbidity: } \\
10 \% \text { current MDD, } 30 \% \text { past } \\
\text { MDD, I0\% social phobia, } \\
25 \% \text { specific phobia } \\
\text { Physical comorbidity: } \\
\text { unspecified }\end{array}$ & $\begin{array}{l}\text { Duration: } 16 \text { weeks } \\
\text { Weeks 0-8: benzodiazepine } \\
\text { (alprazolam }[A] \text { ) or pill- } \\
\text { placebo (P), with live } \\
\text { exposure }(E) \text { or with } \\
\text { relaxation }(R)(R= \\
\text { psychological-placebo). } \\
\text { Weeks } 9-16: A \text { A } P \text { tapered } \\
\text { to zero, no } E \text { or } R \text { given. } \\
\text { i.e. } 4 \text { groups: AR, AE, PR, PE } \\
A R=\text { bz alone } \\
A E=\text { bz+psychotherapy } \\
P R=\text { double placebo } \\
P E=\text { psychotherapy alone } \\
\text { I. Benzodiazepine mean dose } \\
\text { 5.8 mg/day) } \\
\text { 2. Psychotherapy or placebo } \\
=2 \text { hours live exposure or } \\
\text { relaxation } 6 \text { sessions }\end{array}$ & None & $\begin{array}{l}\text { Assessments "at the end of } \\
\text { acute treatment" gathered at } \\
2 \text { weeks after actual } \\
\text { treatment termination. Long- } \\
\text { term follow-up at } 7 \text { months } \\
\text { after treatment termination. }\end{array}$ & $\begin{array}{l}\text { 'Very much' or 'much' } \\
\text { improved on Clinician's CGI. } \\
\text { Numbers of responders } \\
\text { calculated using normal curve } \\
{[36]}\end{array}$ & $\begin{array}{l}\text { Global severity of PD: 7- } \\
\text { point CGI rated by assessors } \\
\text { Panic attack: total number } \\
\text { of major panics per week } \\
\text { Agoraphobia: } 4 \text { phobic } \\
\text { targets avoidance } \\
\text { General anxiety: 14-item } \\
\text { HAM-A } \\
\text { Depression: 17-item HAM- } \\
\text { D Social functioning: 9-point } \\
\text { assessor-rated scale for } \\
\text { work, social, and family } \\
\text { adjustment }\end{array}$ \\
\hline Wardle $1994[41]$ & $\begin{array}{l}\text { Diagnosis: ICD-9 and DSM- } \\
\text { III-R AG } \\
\text { Mean duration: II-12 } \\
\text { years } \\
\text { Mean age: } 41-45 \text { years in } \\
\text { each arm } \\
82 \% \text { female } \\
\text { Psychiatric co morbidity: } \\
\text { Not specified } \\
\text { Excluded if had comorbid } \\
\text { heart disease, alcohol } \\
\text { problems, drug abuse, } \\
\text { pregnancy or anticipated } \\
\text { pregnancy, or major } \\
\text { psychotic illness }\end{array}$ & $\begin{array}{l}\text { Duration: } 16 \text { weeks } \\
16 \text { weeks for benzodiazepine } \\
\text { (with drug taper) and } 8 \\
\text { weeks for psychotherapy } \\
\text { (week } 4-12 \text { ) } \\
\text { l. Diazepam (the dose was } \\
\text { kept to } 5 \mathrm{mg} / \text { day unless the } \\
\text { patient requested an } \\
\text { increase) + BT (eight } 2 \text {-hour } \\
\text { sessions over a } 7 \text { week } \\
\text { period by a clinical } \\
\text { psychologists). Medication } \\
\text { was tapered to zero from } \\
\text { week } 13 \text { to } 16 \text {. } \\
\text { 2. BT + placebo drug }\end{array}$ & None & $\begin{array}{l}\text { At I, } 6,12 \text { months after } \\
\text { treatment discontinuation } \\
\text { Patients were advised to } \\
\text { continue self-exposure. After } \\
\text { the acute treatment phase, } \\
\text { all patients were withdrawn } \\
\text { during } 0 \text {-I month after } \\
\text { treatment discontinuation. } \\
\text { No further treatment was } \\
\text { offered over the follow-up } \\
\text { period unless the patient's } \\
\text { clinical condition } \\
\text { necessitated intervention. }\end{array}$ & $\begin{array}{l}50 \% \text { reduction on MAL from } \\
\text { the baseline by looking at the } \\
\text { raw data }\end{array}$ & $\begin{array}{l}\text { Global severity of panic } \\
\text { disorder: MAL } \\
\text { Panic attack: Panic } \\
\text { frequency in past week } \\
\text { Agoraphobia: MAL } \\
\text { General anxiety: STAIS-T } \\
\text { Depression: BDI } \\
\text { Social functioning: Not } \\
\text { applicable }\end{array}$ \\
\hline
\end{tabular}




Acute phase
treatment (at 2-4
months)

Global severity
Frequency of panic
attacks

SMD 2

Phobic avoidance

SMD

2

122

$0.15[-0.21,0.50]$

$0.09[-0.27,0.45]$

\section{General anxiety}

SMD

2

SMD

60

$0.08[-0.43,0.59]$

\section{Depression}

$$
\text { SMD }
$$

$0.17[-0.23,0.58]$

Social functioning

SMD

Dropouts for any reason within 2-4

Dropouts due to side effects within 2-4

RR

months

Immediately after

Response

RR

166

$0.81[0.47,1.38]$

0

Not estimable

166

$0.78[0.45,1.35]$

99

\section{Global/Avoidance/$$
\text { Panic }
$$

SMD

6-12 months after

Response

RR

2

2

166

$-0.31[-0.71,0.09]$

$0.62[0.36,1.07]$

95

$-0.19[-0.59,0.22]$

2

Plobal/A
Panic

SMD

$\mathrm{Cl}$ : confidence interval; RR: relative risk; SMD: standardized weighted mean difference 


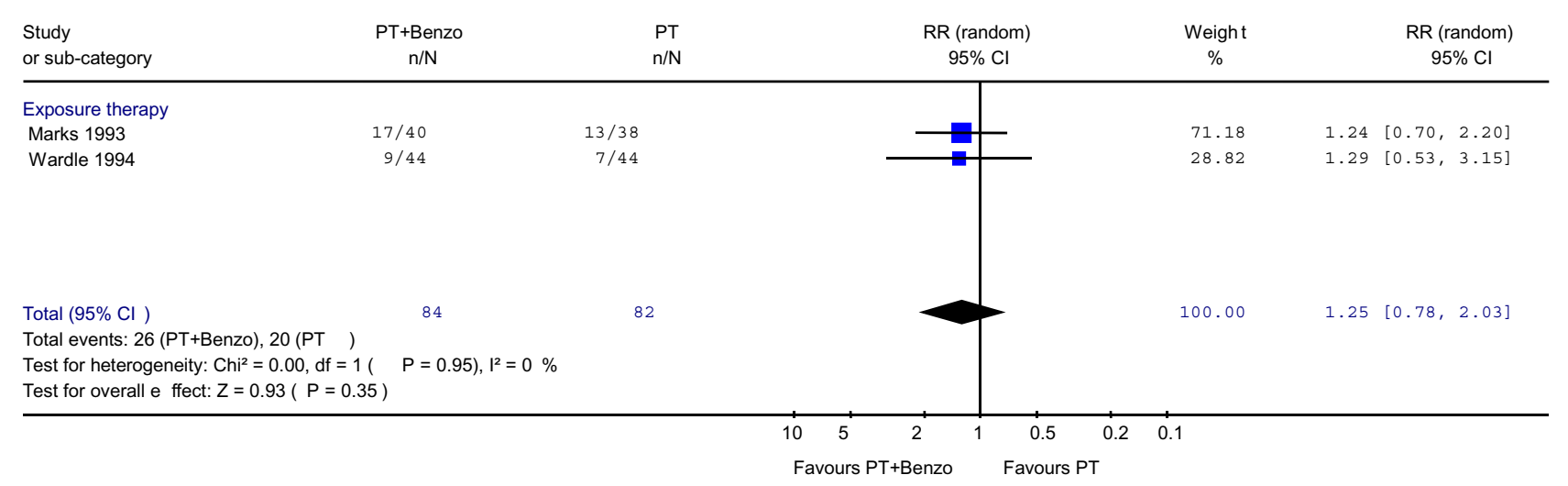

\section{Figure I}

Psychotherapy plus benzodiazepine vs. psychotherapy alone: response at 2-4 months during acute phase treatment. Relative risk of response was calculated using both CGI [20] and Mobility Alone [4I].

$0.78,95 \%$ CI: 0.45 to $1.35 ; \mathrm{P}=0.37$ ) (Figure 3 ). No heterogeneity was observed $\left(\chi^{2}=0.05, \mathrm{df}=1, \mathrm{P}=0.82 ; \mathrm{I}^{2}=\right.$ $0.0 \%)$. In terms of the global severity, weak trend of inferiority of the combination therapy was observed (SMD $0.31,-0.71$ to $0.09, \mathrm{P}=0.12$ ) (Figure 4 ).

\section{Long-term after treatment termination}

At either 12 [41] or 7 [20] months of naturalistic followup after treatment termination, the RR of response rate showed a trend in favour of psychotherapy alone over combination ( $\mathrm{RR}=0.62,95 \% \mathrm{CI}$ : 0.36 to $1.07 ; \mathrm{P}=0.08)$ (Figure 5). No heterogeneity was observed $\left(\chi^{2}=0.01, \mathrm{df}=\right.$ $\left.1, \mathrm{P}=0.93 ; \mathrm{I}^{2}=0.0 \%\right)$. In terms of the global severity, this trend was not observed (SMD $-0.19,-0.59$ to $0.22, \mathrm{P}=$ 0.37 ) (Figure 6).

\section{Psychotherapy plus Benzodiazepine versus}

Benzodiazepine treatment

Acute phase treatment

Comparing combined psychotherapy plus benzodiazepine with benzodiazepine alone in one comparison [20], the RR for response for the combination was 1.57 (95\%CI: 0.83 to $2.98 ; \mathrm{P}=0.17$ ) at 2 months during acute phase treatment (Table 3 ), which was not statistically significant.

The significant superiority of the combination therapy was observed for some secondary outcomes including global severity of the disorder (SMD $0.63 ; 95 \%$ CI 0.14 to 1.11 ), phobic avoidance (SMD $1.17 ; 0.65$ to 1.68$)$ and social functioning (SMD 1.80; 0.99 to 2.61). There was no

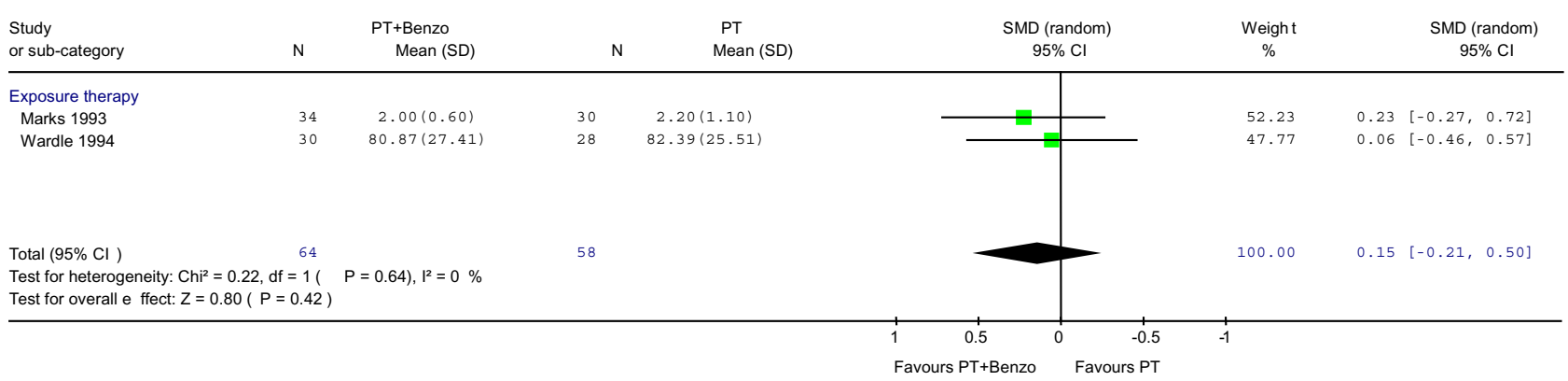

\section{Figure 2}

Psychotherapy plus benzodiazepine vs. psychotherapy alone: global severity at 2-4 months during acute phase treatment. Standardised mean difference was calculated using both CGI [20] and Mobility Alone [4I]. 


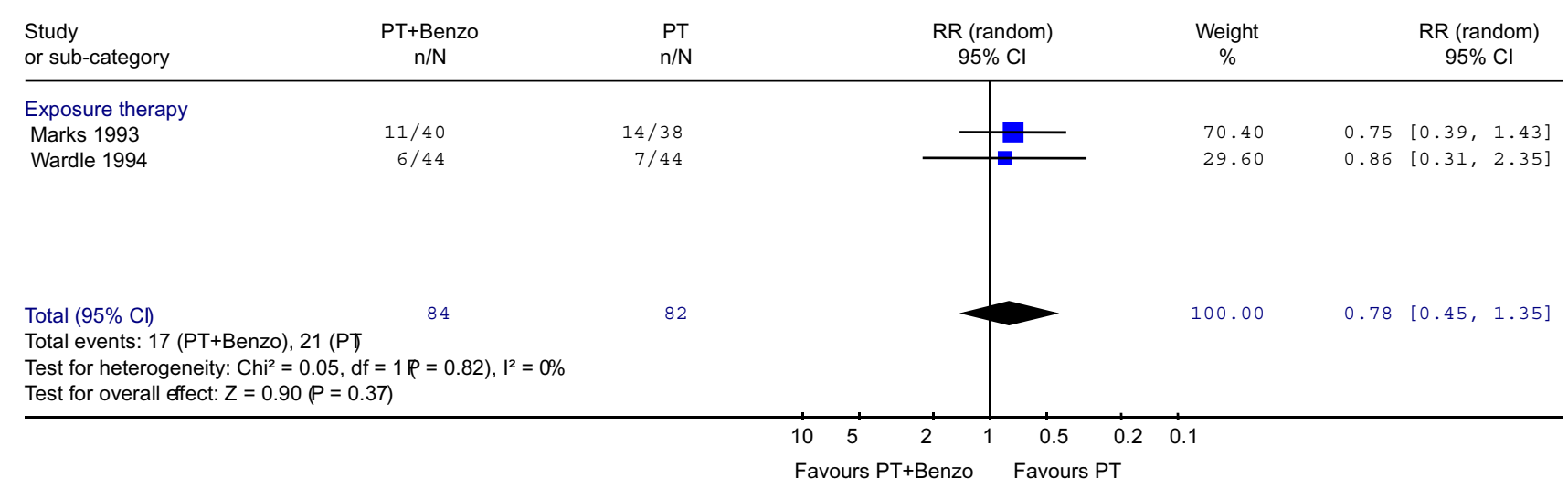

\section{Figure 3}

Psychotherapy plus benzodiazepine vs. psychotherapy alone: response after the end of acute treatment. Relative risk of response was calculated using both CGI [20] and Mobility Alone [4I].

significant difference between both arms in frequency of panic attacks and depression.

No difference was observed in the overall dropouts either.

After the end of acute phase treatment

Superiority of combination to benzodiazepine alone was observed both in the response rate $(\mathrm{RR}=3.39,95 \% \mathrm{CI}$ : 1.03 to $11.21, \mathrm{P}=0.05)$ and the global severity ( $\mathrm{SMD}=$ $0.75,95 \% \mathrm{CI}: 0.19$ to $1.31, \mathrm{P}=0.009$ ).

Long-term after treatment cessation

In terms of response after 7 months after treatment cessation, a weak trend in favour of the combination therapy
$(\mathrm{RR}=2.31,95 \% \mathrm{CI}: 0.79$ to $6.74, \mathrm{P}=0.12)$ in terms of response rates, and a statistically significant superiority of the combination in terms of global severity was observed.

\section{Subgroup and sensitivity analyses}

Due to the limited number of comparisons available, it was not possible to undertake any subgroup analyses or sensitivity analyses.

\section{Discussion}

Despite extensive literature searches and personal communication, only two rigorous studies were identified that examined combined benzodiazepines and psychotherapy for panic disorder.

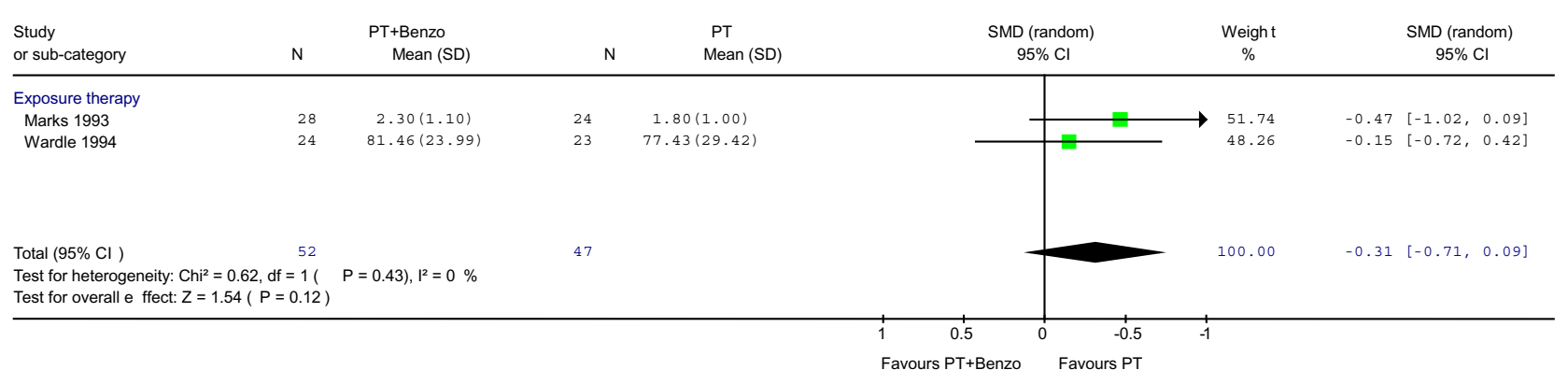

\section{Figure 4}

Psychotherapy plus benzodiazepine vs. psychotherapy alone: global severity after the end of acute treatment. Standardised mean difference was calculated using both CGI [20] and Mobility Alone [4I]. 


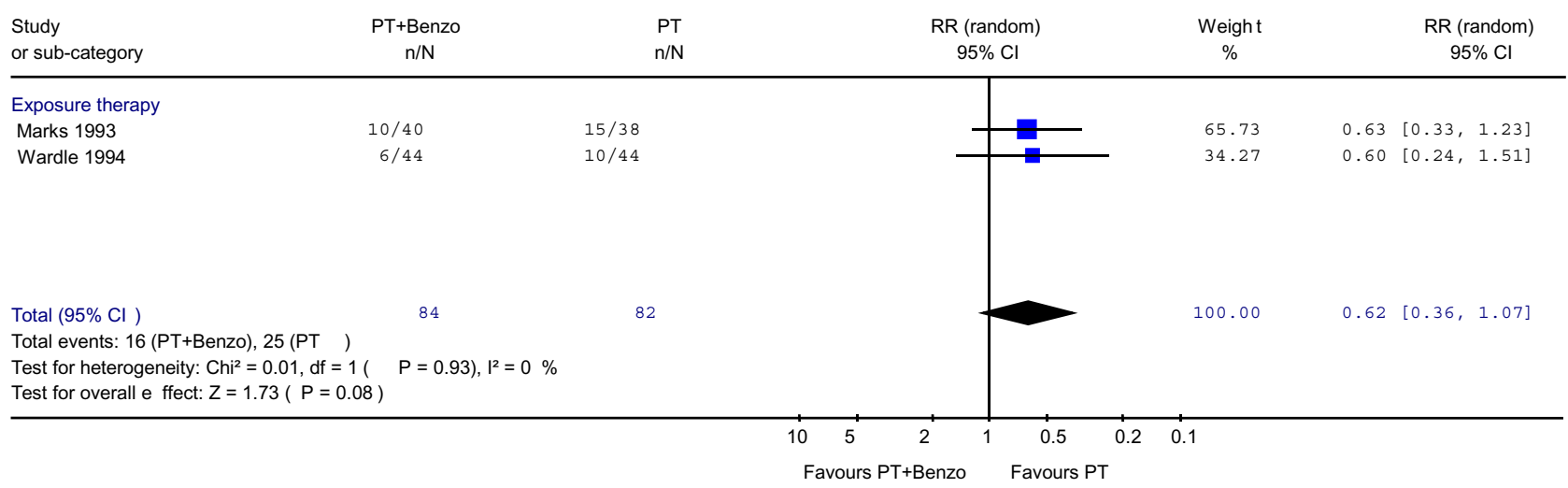

Figure 5

Psychotherapy plus benzodiazepine vs. psychotherapy alone: response at 6-I 2 months after treatment termination. Relative risk of response was calculated using both CGI [20] and Mobility Alone [4I].

What little evidence there is suggests, however, that behaviour therapy (exposure) plus benzodiazepines may be superior to benzodiazepines alone, especially at the end of acute treatment ( $R R=3.39,1.03$ to 11.21), and possibly also during the acute phase and at long-term follow-up. The combined therapy may also be superior to behaviour therapy alone during the acute phase, but this possible superiority may not persist and perhaps invert during the follow-up 6-12 months after treatment termination.

With respect to combination therapy versus benzodiazepines alone, secondary endpoints representing continuous measures also hint at the superiority of the combination during the acute phase treatment, in that the combination was significantly superior to benzodiazepines in terms of the global severity, phobic avoidance, and social functioning. Over the long term, this superiority was not statistically significant $(R R=2.31,0.79$ to 6.74). However, the secondary outcome demonstrated combination therapy was significantly superior to benzodiazepine alone. In addition, data from one of the included RCTs indicated that even placebo was not inferior to behaviour therapy alone or benzodiazepine alone for panic attacks as opposed to phobias and disability, for which placebo was indeed inferior. [20].

With regard to behaviour therapy alone, some secondary endpoints hinted at the superiority of the combination during the acute phase treatment (frequency of panic

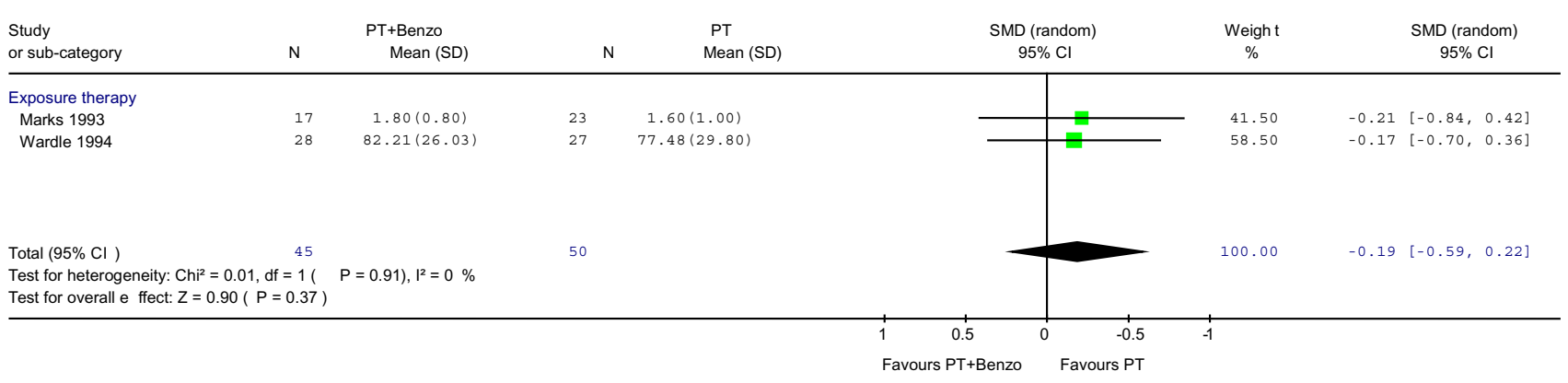

\section{Figure 6}

Psychotherapy plus benzodiazepine vs. psychotherapy alone: global severity at 6-I 2 months after treatment termination. Standardised mean difference was calculated using both CGI [20] and Mobility Alone [4I]. 
attack, social functioning). Some authors have argued that the combination therapy is superior to psychotherapy alone in the long term $[28,31]$. However the results in the present review failed to reach statistical significance in terms of response rate ( $\mathrm{RR}=0.62,0.36$ to $1.07, \mathrm{P}=0.08$ ) or the secondary outcome representing global severity of panic attacks $(\mathrm{SMD}=-0.19,-0.59$ to $0.22, \mathrm{P}=0.37)$.

Considering these results, benzodiazepine alone is not to be recommended for those who have access to appropriate resources of behaviour therapy.

We did not focus on the combined antidepressants and psychotherapy in the present review, but our companion systematic review on this topic also concluded that either combined therapy or psychotherapy alone rather than antidepressants alone might be chosen as first-line treatment for panic disorder with or without agoraphobia [6]. Combining the conclusions of the two reviews, pharmacotherapy alone, be it by an antidepressant or by a benzodiazepine, may be avoided in treatment for panic disorder where psychotherapy is available.

One has to note some possible weaknesses in the present review. First of all, only two studies including 243 patients diagnosed as panic disorder with agoraphobia were identified, type II errors were therefore likely and even the significant results might have limited generalizability. Moreover, we were not able to do any analysis on panic disorder without agoraphobia and managed only to establish very limited evidence for panic disorder with agoraphobia. Secondly, generalizability of the present findings beyond specialist psychiatric settings is not straightforward. The included studies were conducted at psychiatric hospitals under psychiatrists' and clinical psychologists' administration $[20,41]$, so that generalizability of the results of the present review to primary care may be questioned. Another concern on generalizability of the review may arise from the fact that participants were limited to those having been able to tolerate being off medication before entering the study in one study [20]. In addition, regarding use of benzodiazepines, one included study employed a huge daily dose of alprazolam in both the benzodiazepine arms [20] compared to the dose usually recommended in clinical practice, and this could have had negative effects on these arms. The other included study [41] used diazepam as benzodiazepine in relatively lower dose compared to previous studies which involved diazepam as treatment for panic disorder [55-58]. Although diazepam has been demonstrated not only superior to pill-placebo but also equally effective compared with alprazolam [56,58], this issue could have diminished efficacy of diazepam and have diluted differences between combined therapy and psychotherapy alone. Thirdly, the definition of "response" employed in the present study differs from study to study, due to reported outcomes in the original reports. Clinical global rating was employed in one study [20] and phobic avoidance scale in the other [41]. The proportions of responders are much smaller in one study [41] than the other [20], possibly due to different definitions of response. Although no significant heterogeneity has been observed through the analyses in the present review, one might think these definitions are arbitrary or plausible. However, we failed to obtain clinical global scale in the latter [41] in spite of contacting the original authors. We therefore utilized only phobic avoidance scale to define the response, since this has been shown to better represent the patients' global status [34]. Last but not least, all the included studies dealt with psychotherapy in the form of exposure therapy. Other forms of psychotherapies including cognitive restructuring and psychodynamic therapy also need to be examined in combination with benzodiazepines.

On the other hand, the present review may have several strengths. First, we performed a systematic and comprehensive search for the relevant trials. All references to possible candidate studies were investigated to identify relevant ones. The authors of the included studies were contacted to give more information about their studies and other possibly relevant ones. Consequently, our analyses managed to include some unpublished data (MAL) in one study [41]. Second, though there are many narrative reviews on efficacy of combination therapy against either monotherapy that included both high-quality and low-quality studies all together, we limited our systematic review only to high quality RCTs. These RCTs were also conducted while keeping assessors blind. Our approach minimized bias and therefore offered more rigorous evidence. Third, we applied strict ITT principle, by means of imputing response rates from continuous measures of global severity for panic disorder and counting all the dropouts as non-responders, as we were interested in the fate of all patients who began the acute phase after randomisation, not just those who completed it. Counting dropouts as non-responders might appear too stringent as some dropouts may have improved, but we cannot confirm their percentage. Given this circumstance, this approach is the most conservative estimate of the response rate, and in the absence of any stronger and more rational alternative, we decided to remain conservative with regard to either treatment arm.

\section{Conclusion}

In conclusion, we would like to make some recommendations both for clinicians and for researchers as follows. 


\section{Implications for practice}

Currently, there is inadequate evidence to assess the clinical effects of combined benzodiazepine and psychotherapy treatment for patients who are diagnosed as panic disorder with agoraphobia, and no rigorous RCT exists for panic disorder without agoraphobia or for psychotherapy other than exposure therapy. Based on this limited evidence, exposure therapy may be recommended for patients with agoraphobia who have access to appropriate resources. Benzodiazepine alone is not to be recommended for those in such a situation. It seems possible that combined therapy is superior to exposure therapy alone in the acute treatment, but after the acute treatment is terminated, this trend may be reversed.

\section{Implications for research}

More high-quality trials for combined benzodiazepine and psychotherapy treatment must be conducted before making any stronger treatment recommendation.

\section{Competing interests}

TAF has received several research grants and fees for speaking from a pharmaceutical company, which markets a benzodiazepine (ethyl loflazepate). RC and NW have no conflict of interest to declare.

\section{Authors' contributions}

NW contributed to the concept and design, the development of the review protocol, the literature search, the selection of trials, the quality assessments of the trials, the data extraction, inputting the data to the statistical software, the data analysis, and wrote the first draft of the manuscript.

RC contributed to the development of the review protocol, the selection of trials, and the data extraction.

TAF contributed to the development of the review protocol, the literature search, the selection of trials, the quality assessments of the trials, and the data analysis.

All authors contributed to the interpretation of the results, critically revised and approved the final manuscript.

\section{Acknowledgements}

We thank the CCDAN editorial team for their great assistance.

\section{References}

I. Kessler RC, McGonagle KA, Zhao S, Nelson CB, Hughes M, Eshleman $S$, Wittchen HU, Kendler KS: Lifetime and I 2-month prevalence of DSM-III-R psychiatric disorders in the United States. Results from the National Comorbidity Survey. Arch Gen Psychiatry 1994, 5 I (I):8-19.

2. Carlbring P, Gustafsson H, Ekselius L, Andersson G: I2-month prevalence of panic disorder with or without agoraphobia in the Swedish general population. Soc Psychiatry Psychiatr Epidemiol 2002, 37(5):207-2II.
3. Kessler RC, Chiu WT, Demler O, Walters EE: Prevalence, severity, and comorbidity of I2-month DSM-IV disorders in the National Comorbidity Survey Replication. Arch Gen Psychiatry 2005, 62(6):617-627.

4. Beck AT, Sokol L, Clark DA, Berchick R, Wright F: A crossover study of focused cognitive therapy for panic disorder. $\mathrm{Am} J$ Psychiatry 1992, I49(6):778-783.

5. American Psychiatric Association: Practice guideline for the treatment of patients with panic disorder. Work Group on Panic Disorder. Am J Psychiatry I 998, I 55(5 Suppl ): I-34.

6. Furukawa TA, Watanabe N, Churchill R: Psychotherapy plus antidepressant for panic disorder with or without agoraphobia: systematic review. Br J Psychiatry 2006, I88:305-312.

7. Sanderson WC, Wetzler S: Observations on the cognitive behavioral treatment of panic disorder: impact of benzodiazepines. Psychotherapy 1993, 30(I): I25-132.

8. Bandelow B, Sievert K, Rothemeyer M, Hajak G, Ruther E: What treatments do patients with panic disorder and agoraphobia get? Eur Arch Psychiatry Clin Neurosci 1995, 245(3): I65-I7I.

9. Andersch S, Rosenberg NK, Kullingsjo $H$, Ottosson JO, Bech $P$, Bruun-Hansen J, Hanson L, Lorentzen K, Mellergard M, Rasmussen S, et al: Efficacy and safety of alprazolam, imipramine and placebo in treating panic disorder. A Scandinavian multicenter study. Acta Psychiatr Scand Suppl 1991, 365:18-27.

10. Rickels K, Schweizer E: Panic disorder: long-term pharmacotherapy and discontinuation. J Clin Psychopharmacol 1998, I8(6 Suppl 2): I2S-I8S.

II. Barker MJ, Greenwood KM, Jackson M, Crowe SF: Cognitive effects of long-term benzodiazepine use: a meta-analysis. CNS Drugs 2004, I 8(I):37-48.

12. Neutel Cl: Risk of traffic accident injury after a prescription for a benzodiazepine. Ann Epidemiol 1995, 5(3):239-244.

13. Neutel Cl, Hirdes JP, Maxwell CJ, Patten SB: New evidence on benzodiazepine use and falls: the time factor. Age Ageing 1996, 25(4):273-278.

14. Schweizer E, Rickels K: Benzodiazepine dependence and withdrawal: a review of the syndrome and its clinical management. Acta Psychiatr Scand Suppl 1998, 393:95-101.

15. Pecknold JC, Swinson RP, Kuch K, Lewis CP: Alprazolam in panic disorder and agoraphobia: results from a multicenter trial. III. Discontinuation effects. Arch Gen Psychiatry 1988, 45(5):429-436.

16. Addis ME, Hatgis C, Krasnow AD, Jacob K, Bourne L, Mansfield A: Effectiveness of cognitive - behavioral treatment for panic disorder versus treatment as usual in a managed care setting. J Consult Clin Psychol 2004, 72(4):625-635.

17. Clark DM, Salkovskis PM, Hackmann A, Wells A, Ludgate J, Gelder M: Brief cognitive therapy for panic disorder: a randomized controlled trial. J Consult Clin Psychol 1999, 67(4):583-589.

18. Kenardy JA, Dow MG, Johnston DW, Newman MG, Thomson A, Taylor CB: A comparison of delivery methods of cognitivebehavioral therapy for panic disorder: an international multicenter trial. J Consult Clin Psychol 2003, 7 I (6): I 068-I075.

19. Ito LM, de Araujo LA, Tess VL, de Barros-Neto TP, Asbahr FR, Marks I: Self-exposure therapy for panic disorder with agoraphobia: randomised controlled study of external $v$. interoceptive self-exposure. Br J Psychiatry 200I, I 78:33I-336.

20. Marks IM, Swinson RP, Basoglu M, Kuch K, Noshirvani H, O'Sullivan G, Lelliott PT, Kirby M, McNamee G, Sengun S, et al.: Alprazolam and exposure alone and combined in panic disorder with agoraphobia. A controlled study in London and Toronto. $\mathrm{Br}$ J Psychiatry 1993, I 62:776-787.

21. Telch MJ, Lucas JA, Schmidt NB, Hanna HH, LaNae Jaimez T, Lucas RA: Group cognitive-behavioral treatment of panic disorder. Behav Res Ther 1993, 3 I(3):279-287.

22. Telch MJ, Schmidt NB, Jaimez TL, Jacquin KM, Harrington PJ: Impact of cognitive-behavioral treatment on quality of life in panic disorder patients. J Consult Clin Psychol 1995, 63(5):823-830.

23. Williams SL, Falbo J: Cognitive and performance-based treatments for panic attacks in people with varying degrees of agoraphobic disability. Behav Res Ther 1996, 34(3):253-264.

24. Starcevic V, Linden M, Uhlenhuth EH, Kolar D, Latas M: Treatment of panic disorder with agoraphobia in an anxiety disorders clinic: factors influencing psychiatrists' treatment choices. Psychiatry Res 2004, I 25(I):4|-52. 
25. Spiegel DA, Bruce T]: Benzodiazepines and exposure-based cognitive behavior therapies for panic disorder: conclusions from combined treatment trials. Am J Psychiatry 1997 | 54(6):773-78|.

26. Westra HA, Stewart SH: Cognitive behavioural therapy and pharmacotherapy: complementary or contradictory approaches to the treatment of anxiety? Clin Psychol Rev 1998, I 8(3):307-340.

27. Wardle J: Behaviour therapy and benzodiazepines: allies or antagonists? BrJ Psychiatry 1990, I 56:163-168.

28. Brown TA, Barlow DH: Long-term outcome in cognitivebehavioral treatment of panic disorder: clinical predictors and alternative strategies for assessment. J Consult Clin Psychol 1995, 63(5):754-765.

29. Otto MW, Pollack MH, Sabatino SA: Maintenance of remission following cognitive behavior therapy for panic disorder: possible deleterious effects of concurrent medication treatment. Behav Ther 1996, 27:473-482.

30. van Balkom AJ, de Beurs E, Koele P, Lange A, can Dyck R: Longterm benzodiazepine use is associated with smaller treatment gain in panic disorder with agoraphobia. J Nerv Ment Dis 1996, I84(2): I33-135.

31. Westra HA, Stewart SH, Conrad BE: Naturalistic manner of benzodiazepine use and cognitive behavioral therapy outcome in panic disorder with agoraphobia. J Anxiety Disord 2002, 16(3):233-246.

32. Hegel MT, Ravaris CL, Ahles TA: Combined cognitive behavioral and time-limited alprazolam treatment of panic disorder. Behav Ther 1994, 25: 183-195.

33. Oei TP, Llamas M, Evans $L$ : Does concurrent drug intake affect the long-term outcome of group cognitive behaviour therapy in panic disorder with or without agoraphobia? Behav Res Ther 1997, 35(9):85I-857.

34. Basoglu M, Marks IM, Kilic C, Swinson RP, Noshirvani H, Kuch K, O'Sullivan G: Relationship of panic, anticipatory anxiety, agoraphobia and global improvement in panic disorder with agoraphobia treated with alprazolam and exposure. Br J Psychiatry 1994, 164(5):647-652.

35. Higgins JPT, Green S, editors: Cochrane Handbook for Systematic Reviews of Interventions 4.2.5 [Updated May 2005]. In The Cochrane Library 4.2.5 Issue 3 Chichester, UK: John Wiley \& Sons, Ltd; 2005.

36. Furukawa TA, Cipriani A, Barbui $C$, Brambilla $P$, Watanabe $N$ : Imputing response rates from means and standard deviations in meta-analyses. Int Clin Psychopharmacol 2005 20(1):49-52.

37. Furukawa TA, Guyatt GH, Griffith LE: Can we individualize the 'number needed to treat'? An empirical study of summary effect measures in meta-analyses. Int J Epidemiol 2002, $3 I(I): 72-76$

38. Higgins JP, Thompson SG: Quantifying heterogeneity in a metaanalysis. Stat Med 2002, 21 (II): $1539-1558$.

39. Hafner J, Marks I: Exposure in vivo of agoraphobics: contributions of diazepam, group exposure, and anxiety evocation. Psychol Med 1976, 6(I):7I-88.

40. Lopez Alonso JC Gomez-Jarabo G: A model of therapeutic action in panic disorders. The European journal of psychiatry 2000 , I 4(I):42-51.

4I. Wardle J, Hayward P, Higgitt A, Stabl M, Blizard R, Gray J: Effects of concurrent diazepam treatment on the outcome of exposure therapy in agoraphobia. Behav Res Ther 1994, 32(2):203-215.

42. Basoglu M, Marks IM, Kilic C, Brewin CR, Swinson RP: Alprazolam and exposure for panic disorder with agoraphobia. Attribution of improvement to medication predicts subsequent relapse. Br J Psychiatry 1994, 164(5):652-659.

43. Basoglu M, Marks IM, Swinson RP, Noshirvani H, O'Sullivan G, Kuch $\mathrm{K}$ : Pre-treatment predictors of treatment outcome in panic disorder and agoraphobia treated with alprazolam and exposure. J Affect Disord 1994, 30(2): I23-I 32.

44. Basoglu M, Marks I, Livanou M, Swinson R: Double-blindness procedures, rater blindness, and ratings of outcome. Observations from a controlled trial. Arch Gen Psychiatry 1997, 54(8):744-748.
45. Bond AJ, Curran HV, Bruce MS, O'Sullivan G, Shine P: Behavioural aggression in panic disorder after 8 weeks' treatment with alprazolam. J Affect Disord 1995, 35(3): I I7-123.

46. Curran HV, Bond A, O'Sullivan G, Bruce M, Marks I, Lelliot P, Shine $P$, Lader $M$ : Memory functions, alprazolam and exposure therapy: a controlled longitudinal study of agoraphobia with panic disorder. Psychol Med 1994, 24(4):969-976.

47. Kilic C, Curran HV, Noshirvani H, Marks IM, Basoglu M: Long-term effects of alprazolam on memory: a 3.5 year follow-up of agoraphobia/panic patients. Psychol Med I999, 29(I):225-23I.

48. Klein DF: Panic disorder with agoraphobia. BrJ Psychiatry 1993 , 163:835-837.

49. Marks IM, Basoglu M, Noshirvani H, Greist J, Swinson RP, O'Sullivan $\mathrm{G}$ : Drug treatment of panic disorder. Further comment. $\mathrm{Br}$ Psychiatry 1993, 162:795-796.

50. O'Sullivan GH, Noshirvani H, Basoglu M, Marks IM, Swinson R, Kuch $\mathrm{K}$, Kirby M: Safety and side-effects of alprazolam. Controlled study in agoraphobia with panic disorder. $\mathrm{Br} \int$ Psychiatry 1994 165(2):79-86

5I. O'Sullivan GH, Swinson R, Kuch K, Marks IM, Basoglu M, Noshirvan $\mathrm{H}$ : Alprazolam withdrawal symptoms in agoraphobia with panic disorder: observations from a controlled Anglo-Canadian study. I Psychopharmacol 1996, 10(2):101-109.

52. Spiegel DA, Roth M, Weissman M, Lavori P, Gorman J, Rush J, Ballenger J: Comment on the London/Toronto Study of Alprazolam and Exposure in Panic Disorder with Agoraphobia. $\mathrm{Br}$ J Psychiatry 1993, 162:788-789. discussion 790-784

53. Hayward P, Wardle J, Higgitt A, Gray J: Changes in "withdrawa symptoms" following discontinuation of low-dose diazepam. Psychopharmacology (Berl) 1996, I25(4):392-397.

54. Chambless DL, Caputo GC, Jasin SE, Gracely EJ, Williams C: The Mobility Inventory for Agoraphobia. Behav Res Ther 1985, 23(I):35-44.

55. Pohl $\mathrm{R}$, Balon $\mathrm{R}$, Berchou $\mathrm{R}$, Lycaki $\mathrm{H}$ : Lactate-induced anxiety after imipramine and diazepam treatment. Anxiety 1994, I(2):54-63.

56. Dunner DL, Ishiki D, Avery DH, Wilson LG, Hyde TS: Effect of alprazolam and diazepam on anxiety and panic attacks in panic disorder: a controlled study. J Clin Psychiatry 1986, 47(9):458-460.

57. Noyes R Jr, Anderson DJ, Clancy J, Crowe RR, Slymen DJ, Ghoneim MM, Hinrichs JV: Diazepam and propranolol in panic disorder and agoraphobia. Arch Gen Psychiatry 1984, 4I(3):287-292.

58. Noyes R Jr, Burrows GD, Reich JH, Judd FK, Garvey MJ, Norman TR, Cook BL, Marriott P: Diazepam versus alprazolam for the treatment of panic disorder. J Clin Psychiatry 1996, 57(8):349-355.

59. Chambless DL, Foa EB, Groves GA, Goldstein A): Exposure and communications training in the treatment of agoraphobia. Behav Res Ther 1982, 20(3):219-231.

60. Chouinard G, Annable L, Fontaine R, Solyom L: Alprazolam in the treatment of generalized anxiety and panic disorders: a double-blind placebo-controlled study. Psychopharmacology (Berl) 1982, 77(3):229-233.

61. Craske MG: Models and treatment of panic: behavioural therapy of panic. Journal of cognitive psychotherapy 199|, 5(3): 199-2/4.

62. Echeburua E, De Corral P, Garcia Bajos E, Borda M: Interactions between self-exposure and alprazolam in the treatment of agoraphobia without current panic: an exploratory study. Behavioural and Cognitive Psychotherapy 1993, $21: 2$ 19-38.

63. Johnston D, Gath D: Arousal levels and attribution effects in diazepam-assisted flooding. $\mathrm{Br}\rfloor$ Psychiatry 1973 , I 23(575):463-466.

64. Otto MW, Pollack MH, Sachs GS, Reiter SR, Meltzer-Brody S, Rosenbaum JF: Discontinuation of benzodiazepine treatment: efficacy of cognitive-behavioral therapy for patients with panic disorder. Am J Psychiatry 1993, I 50(I0): | 485-1490.

65. Riley WT, McCormick M, Simon EM, Stack K, Pushkin Y, Overstreet $M M$ : Effects of alprazolam dose on the induction and habituation processes during behavioral panic induction treatment. J Anxiety Disord 1995, 9(3):217-227.

66. Spiegel DA, Bruce TJ, Gregg SF, Nuzzarello A: Does cognitive behavior therapy assist slow-taper alprazolam discontinuation in panic disorder? Am J Psychiatry 1994, 15 I (6):876-88I. 
67. Whitehead WE, Robinson A, Blackwell B, Stutz RM: Flooding treatment of phobias: does chronic diazepam increase effectiveness? J Behav Ther Exp Psychiatry 1978, 9:21 9-225.

\section{Pre-publication history}

The pre-publication history for this paper can be accessed here:

http://www.biomedcentral.com/1471-244X/7/18/pre

pub

Publish with Bio Med Central and every scientist can read your work free of charge

"BioMed Central will be the most significant development for disseminating the results of biomedical research in our lifetime. " Sir Paul Nurse, Cancer Research UK

Your research papers will be:

- available free of charge to the entire biomedical community

- peer reviewed and published immediately upon acceptance

- cited in PubMed and archived on PubMed Central

- yours - you keep the copyright

Submit your manuscript here:

http://www.biomedcentral.com/info/publishing_adv.asp
BioMedcentral 